intervertebral joint space widens. Hence intermittent or pulsating traction acts merely on muscles, evoking the stretch reflex but not the suction that determines the effect on the protrusion.

The absolute contraindication to traction is acute lumbago. ${ }^{2}$ Though pain and signs cease while the pull is maintained, the slightest diminution in tension causes such agonising twinges that it takes several hours to get the patient off the couch, and some aggravation lasts several days. I have also emphasised in succeeding editions of my book that traction is valueless (though not harmful, as in acute lumbago) in sciatica with neurological deficit. Impaired conduction shows that the bulge has become larger than the aperture whence it emerged; reduction by manipulation or traction is now impossible. This view was corroborated by a controlled trial in Norway. ${ }^{3}$ As for the "nipped synovial fringe" dear to those who attribute back troubles to disorders of the facet joints, the plain fact is that synovial membrane is devoid of nerves and pain cannot arise from it.

By all means let us have trials, as $\mathrm{Dr} B \mathrm{O}$ Scott suggests (31 January, p 284), but let them be designed to establish new facts or to investigate findings as yet uncorroborated.

\section{London W1}

JAMEs CyriaX

1 Cyriax, J H, British Medical fournal, 1950, 2, 1436. p 450 . London, Baillière Tindall 1954

p 450. London, Bailliere Tindall, 1954.
Weber, H, fournal of the Oslo City Hospitals, 1973, 23,
167.

\section{Cancer statistics}

SIR,-May I reply to some of the criticisms made by Professor $M R$ Alderson and by Dr L J Kinlen and Professor M P Vessey (31 January, p 280) concerning my recent paper (10 January, p 86).

Professor Alderson ${ }^{1}$ has discussed some of the problems of medical information systems, but many difficulties still remain. Any alteration in a national registration system, whether it be for cancer or motor vehicle licences, involves a great deal of work which can be justified only if the result promises to be worth while. Collection of detailed data from original case notes is not impossible and is achieved at some large hospitals such as the Royal Marsden Hospital and Institute of Cancer Research, London, and the Christie Hospital and Holt Radium Institute, Manchester. The difficulties are then those of data abstraction, storage, and retrieval. Regional registries often lack staff to perform any but the most immediate tasks; they do not lack enthusiasm.

Both Professor Alderson and Dr Kinlen and Professor Vessey imply that I had either overlooked or minimised the value of epidemiological studies compared with that of survival rate investigations. I can only reply that perhaps a better title for my paper would have been "Cancer treatment statistics," since it was with this topic only that I was concerned in that communication. Indeed, I have recently used registry data for an epidemiological study of incident age distribution for cancer of the cervix in England and Wales, $1945-69^{2}$, and I am also well aware of the excellent epidemiological work which is produced by Professor Doll's departments in Oxford.
In reply to $\mathrm{Mr} F \mathrm{E}$ Whitehead (24 January, p 223) concerning $\mathrm{SH} 3$ returns I would like to make three points. (1) Consultation statistics (part 2, line 18) and treatment statistics (part 3 , line E) are given for both new outpatients (that is, numbers of persons) and outpatient attendances (that is, numbers of visits). This makes a total of four radiotherapy outpatient statistics on each $\mathrm{SH} 3$ return, in addition to any inpatient statistics. (2) My communication referred only to numbers of new outpatients, whereas $\mathrm{Mr}$ Whitehead's comments were mainly based on information relevant to outpatient attendances. I would agree that attendance figures in parts 2 and 3 will almost inevitably differ, but this is not the point in question. Although the first attendance of a cancer outpatient in a radiotherapy department may be for treatment, the need having been confirmed elsewhere, by the nature of most treatment schedules the patient will be attending for treatment over a period of weeks, and consultation with the medical staff of the radiotherapy department is normally bound to occur. In this case the patient will count once as a new outpatient in part 2 of $\mathrm{SH} 3$, since he will receive a series of consultation attendances, and will also count once as a new outpatient in part 3 of $\mathrm{SH} 3$, because he is attending a number of times for treatment. (3) $\mathrm{Mr}$ Whitehead refers to both radiology and radiotherapy departments, although only radiotherapy statistics are under discussion.

\section{Westminster Medical School,
London, SW 1}

R F MOULD

Alderson, M R, in Central Government Review Health Statistics, Vol 2, Review of UK Statistical Sources, ed W F Maunder. London, Heinemann, 1974.

Mould, R F, fournal of Obstetrics and Gynaecology of the British Commonwealth, 1974, 81, 644.

\section{Changing patterns of cancer}

SIR,-Perhaps the most interesting observation in the changing pattern of bronchial carcinoma (leading article, 7 February, p 301) is a fall in the incidence of the disease in the younger age groups in both sexes. The rates started to fall in men up to the age of 49 in 1950 and it fell steadily between 1969 and 1972 in women under the age of 45.1

Is it certain that this fall is entirely due to changing smoking habits? The men reached their present level of consumption in 1940 , and their annual consumption per head over the age of 15 has remained reasonably steady since then at just under 4000 cigarettes per year; the consumption amongst the women is still rising and reached 2560 by the end of $1972 .{ }^{2}$ If a comparison is made between the average consumption among women who reached 45 ten years ago and those now reaching that age it can be shown that the latter had substantially higher cigarette consumption per head than that of their elder sisters, the difference being in the order of $3: 2$, but they have a falling incidence of bronchial carcinoma. Surely there must be another factor at work.

J R BELCHER

The London Chest Hospital,

\section{London E2}

1 Office of Population Censuses and Surveys, Registrar General's Statistical Review of England and Wales,

Todd, G F, Changes in Smoking Habits in the UK, Tobacco Research Coun

\section{Nucleus hospitals}

SIR,-Your leading article (31 January, p 245) criticises the concept of nucleus hospitals, suggesting that community hospitals are going to be unable to act as supporting units. You cannot seriously suggest that "all patients admitted on medical grounds to hospital nowadays require the kind of support from laboratory and technical services that can best be provided in one large unit rather than half a dozen small ones." I presume that the urban counterpart of those patients cared for in existing rural community hospitals are being admitted to the medical wards of urban district general hospitals. Do they really need such sophisticated technological support? To suggest this suggests that a considerable number of patients are receiving second-class hospital care.

I agree that effective community hospitals need rehabilitation services and good domicilary community care. Savings on large district general hospitals that may now not be built should go some way towards providing these.

Tewkesbury, Glos

A J Chapman

\section{Psychiatric aspects of shoplifting}

SIR,-I am prompted by Dr J Todd's communication "Pharmacogenic shoplifting ?" (17 January, p 150) to advance some impressions regarding shoplifting.

The practitioner, perhaps helpfully prompted by and widely seeking information from relatives or other workers, can usefully bear in mind possible contributory or explanatory factors, including the following: (1) The pharmacogenic factors mentioned, adding also the "hang-over" effect of night sedation (and indeed the disorganising effect of insomnia itself), the possible side effects of antiepileptic, steroid, or antihistamine therapy, and the confused phases during electric convulsion therapy. (2) Schizophrenic patients-some florid but others offending while being vague or deluded. (3) Depressive states, in which some endogenous cases may well reflect a deliberate desire to be caught-that is, a suicidal equivalent or appeal for help-and other reactive cases with the inattentive patient preoccupied with problems or distress-for example, cases of recent bereavement. (4) Anxiety states with significantly impaired concentration as one aspect of reduced ability to cope normally. (5) Mentally handicapped individuals in whom the lure of glitter and possession is greater than their sadly illdeveloped sense of right and wrong. (6) Organic cases with distraction through physical illness-for example, orthopaedic, neurological, gynaecological, or endocrine, with discomfort and diminished physical skill, or intracranial lesions, head injury, or most frequently, a dementia or pseudodementia with genuine confusion and impairment of memory. (7) An abnormal distracting influence-for example, trying to shop and cope with mentally handicapped or hyperkinetic youngsters. (8) The stress of crowded, bustling, noisy stores compelling the sensitive or claustrophobic patient to "escape," forgetting to pay. (9) Often the combination of several of the above factors which, when considered together, could reasonably constitute "a lack of intent." And finally (10) 